\title{
Tourette's syndrome and associated disorders: a systematic review
}

\author{
Cruzamento de patologias na síndrome de Tourette: uma revisão sistemática
}

Bárbara R. Ferreira, ${ }^{1}$ J. L. Pio-Abreu, ${ }^{2}$ Cristina Januário ${ }^{3}$

Resumo

\begin{abstract}
Objective: To compile data on Tourette's syndrome (TS), tics and associated disorders.

Methods: A systematic review of the literature was conducted using the $5 \mathrm{~S}$ levels of organization of healthcare research evidence (systems, summaries, synopses, syntheses, studies), based on the model described by Haynes. The search keywords were Tourette, tics and comorbidity, which were cross-referenced. Studies provided by publishers and articles being processed on July 31,2013 , were also included.

Results: Of all studies retrieved during the search, 64 were selected because they analyzed the epidemiology, clinical features and etiopathogenesis of TS and its comorbidities. TS is classified as a hyperkinetic movement disorder, and at least $90 \%$ of the patients have neuropsychiatric comorbidities, of which attention deficit hyperactivity and obsessive-compulsive disorders are the most common. The syndrome is clinically heterogeneous and has been associated with a dysfunction of cortico-striatal-thalamic-cortical circuits involving various neurotransmitters. Although its genetic etiology has been widely studied, other factors may be important to understand this syndrome and its associated disorders.

Conclusions: TS is a neurodevelopmental disorder that results from the impact of stress factors on a vulnerable biological substrate during the critical periods of neurodevelopment. The study of TS and its comorbidities may contribute, at different levels, to the understanding of several neuropsychiatric disorders of clinical and therapeutic relevance.

Keywords: Attention deficit disorder with hyperactivity, comorbidity, obsessive-compulsive disorder, tics, Tourette's syndrome.
\end{abstract}

\author{
Objetivo: Compilar o conhecimento existente sobre a síndrome \\ de Tourette (ST), tiques e patologias associadas.
}

Metodologia: Foi realizada uma revisão sistemática da literatura usando os níveis $5 \mathrm{~S}$ (sistemas, sumários, sinopses, sínteses e estudos) de organização de evidência de pesquisa em saúde, com base no modelo proposto por Haynes. Os termos de busca foram Tourette, tiques e comorbidades, completados por pesquisa por referência cruzada. Os artigos fornecidos pelos editores e aqueles a serem processados para publicação em 31 de julho de 2013 também foram incluídos.

Resultados: De todos os artigos encontrados durante a pesquisa, 64 foram selecionados porque analisavam a epidemiologia, as características clínicas e a etiopatogenia da ST. A ST define-se como um distúrbio hipercinético do movimento, e pelo menos $90 \%$ dos pacientes apresentam comorbidades neuropsiquiátricas, das quais as mais comuns são a perturbação de déficit de atenção com hiperatividade e a perturbação obsessivo-compulsiva. Esta síndrome é clinicamente heterogênea e tem sido relacionada com a disfunção dos circuitos córtico-estriado-tálamo-corticais envolvendo vários neurotransmissores. Apesar de sua etiologia genética ter sido amplamente estudada, outros fatores podem ser importantes para entender esta síndrome e as perturbações relacionadas.

Conclusões: A ST resulta de uma perturbação do desenvolvimento neurológico causado pelo impacto de fatores de estresse num substrato biológico vulnerável durante os períodos críticos do desenvolvimento neurológico. O estudo da ST e das suas comorbidades poderá contribuir, em diferentes níveis, para o entendimento de várias perturbações neuropsiquiátricas com relevância clínica e terapêutica.

Descritores: Perturbação de déficit de atenção com hiperatividade, comorbidades, perturbação obsessivo-compulsiva, tiques, síndrome de Tourette.

\footnotetext{
${ }^{1}$ MD, MMed. Coimbra Hospital and University Centre, Coimbra, Portugal. ${ }^{2}$ MD, PhD. Psychiatry Department, Coimbra Hospital and University Centre, Coimbra, Portugal. ${ }^{3}$ MD, PhD. Neurology Department, Coimbra Hospital and University Centre, Coimbra, Portugal.

This article was based on the first author's Master's dissertation entitled "Cruzamento de patologias na síndrome de Tourette" ("Associated pathologies in Tourette's syndrome"), presented at the School of Medicine of Universidade de Coimbra, Portugal, in 2011.

Financial support: none.

Submitted Jan 12 2014, accepted for publication Mar 03 2014. No conflicts of interest declared concerning the publication of this article.

Suggested citation: Ferreira BR, Pio-Abreu JL, Januário C. Tourette's syndrome and associated disorders: a systematic review. Trends Psychiatry Psychother. 2014;36(3):123-133. http://dx.doi.org/10.1590/2237-6089-2014-1003
} 


\section{Introduction}

Tourette's syndrome (TS) is a developmental neuropsychiatric disorder characterized by multiple, brief, recurrent, nonrhythmic movements and one or more vocalizations called tics. The tics may vary in frequency, but persist for more than one year. The formal diagnostic criteria for TS are found in the Diagnostic and Statistical Manual (DSM) of the American Psychiatric Association (APA), the International Classification of Disease and Related Health Problems (ICD) of the World Health Organization (WHO), and the Classification of Tic Disorders (CTD) of the Tourette Syndrome Classification Group (TSCG). Childhood onset is before 21 years according to the TSCG and 18 years according to WHO and APA. ${ }^{1}$ Onset typically occurs during early childhood, and boys are more affected than girls. The severity of tics in children with TS usually declines over the course of adolescence. ${ }^{2}$

TS is the most common cause of tics. ${ }^{3}$ According to recent community-based studies, the prevalence of TS in school-aged children ranges from one to eight per $1,000 .{ }^{4}$ According to Robertson, TS affects at least $1 \%$ of the population worldwide. ${ }^{5,6}$

The etiopathogenesis of TS is unknown, but may be associated with a disturbance in the striatalthalamic-cortical (mesolimbic) pathway, which leads to a disinhibition of the motor and limbic system. TS was thought to be an autosomal dominant disorder, but its pattern of inheritance may be more complex. ${ }^{3}$ Neurobiological and pharmacological data have implicated central monoaminergic and neuropeptidergic systems. Although evidence supports a critical role for dopamine (DA), the involvement of norepinephrine (NE) and corticotropin-releasing factor (CRF) has also been suggested because patients frequently report that tics are more severe during periods of stress. ${ }^{7}$ Recent interest has been focused on the role of two closely related neurosecretory nonapeptides, arginine vasopressin and oxytocin. ${ }^{8}$ Moreover, an altered androgen-dependent process of sexual differentiation during prenatal life may contribute to the development of tics, as a tic disorder in females is associated with a more typically masculine pattern of performance. ${ }^{9}$

Substantial evidence suggests that both environmental and genetic factors contribute to the development and clinical expression of TS. Although genetic studies of TS are common, studies of environmental factors are relatively few, but, for instance, an association between prenatal or perinatal adverse events and TS and its comorbidities has already been pointed out. Recent studies found that at least some cases of TS are immunemediated. ${ }^{10}$ The contribution of psychosocial factors, such as locus of control, has also been investigated. ${ }^{11}$
TS has comorbid disorders in approximately $90 \%$ of all patients, and attention deficit hyperactivity disorder $(A D H D)$ and obsessive-compulsive disorder (OCD) are the most common. ${ }^{12}$ Patients with OCD seem to have different clinical features, and an association between some of these patients and TS has been found. Moreover, several additional comorbidities, such as anxiety, mood and sleep disorders, learning disabilities and disruptive behavior disorders, remain highly prevalent in TS. Other comorbidities, although less common, have also been described.

This systematic review collected up-to-date information about the comorbidities of TS using the $5 \mathrm{~S}$ levels of evidence described by Haynes. ${ }^{13}$ Comorbidities and their prevalence were listed, and their association with TS was analyzed to improve the understanding of TS and its comorbidities.

\section{Methods}

This review included studies published in English, Spanish, French and Portuguese, using the $5 \mathrm{~S}$ model of evidence based on information services, described by Haynes as a pyramid with five levels of evidence ${ }^{13}$ that start in systems, the top level, and go down the pyramid to summaries, synopses, syntheses and studies. The systems level of evidence was not used, as it was not fully developed. Therefore, the summaries was the first level in this review. At this level, the search was carried out in UpToDate and DynaMed using the words Tourette and tics. At the synopses level of evidence, the search was conducted using the same words in the Evidence Based Medicine database, but no specific articles about TS and its comorbidities were retrieved. At the next level of evidence, syntheses, the Cochrane Library and the PubMed Clinical Queries filter were used, and the search for Tourette, tics, Tourette AND comorbidities and tics AND comorbidities in the first, and for Tourette* AND comorbidit* and (tics OR tic) AND comorbidit* in the second retrieved some articles of interest. Duplicate studies were excluded. At the studies level, the search in the Medical Subject Headings (MeSH) of PubMed retrieved studies that used different synonyms for the same concept. More precisely, the search strategy was Tourette syndrome AND comorbidity, limited to studies published from 1990 to 2013 (July 31) in English, French, Spanish or Portuguese. Duplicate studies were excluded, and then the same search was conducted for tics AND comorbidity. Searches using the PubMed MeSH only retrieve studies that have already been indexed, and a different strategy had to be used to find those studies being processed for publication. For that purpose, a search for Tourette* AND comorbidit* was conducted on 
July 31,2013 , and studies supplied by publishers and in process were selected. Finally, a search for tics* AND comorbidit* retrieved the last studies included in this review, which totaled 315 articles (Figure 1).

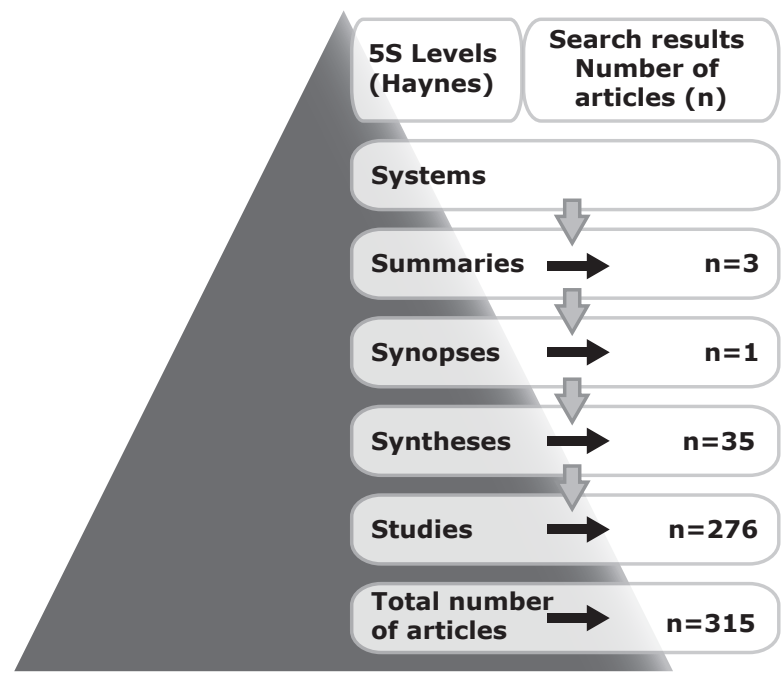

Figure 1 - Schematic illustration of the $5 \mathrm{~S}$ model of evidence-based information services, as described by Haynes. This search retrieved 315 articles after exclusion of duplicates.
Sixty-four articles were evaluated for pertinence and selected according to the following criteria: comorbidities of TS and tics; prevalence of comorbidities in TS; main clinical features of patients; the etiopathogenesis of TS, tics and comorbidities.

\section{Results}

\section{TS and associated disorders: comparative studies of prevalence}

TS seems to be the intersection between numerous, mostly neuropsychiatric disorders.

Table 1 summarizes the seven articles that compare the prevalence of the comorbidities more frequently discussed in the scientific literature on this topic according to this systematic review. ${ }^{1,2,14-18}$

Table 2 shows the prevalence of those comorbidities described in the studies in Table 1.

The most prevalent comorbidity in TS is different in the studies analyzed, particularly between ADHD and other behavior disorders and OCD and other anxiety disorders. ADHD is one of the most prevalent psychiatric disorders in children and, considering the high prevalence of the same spectrum disorders in TS,

Table 1 - TS and associated disorders: comparative studies of prevalence

\begin{tabular}{|c|c|c|c|c|}
\hline \multirow[b]{2}{*}{ Author } & \multicolumn{2}{|c|}{ Study participants } & \multirow{2}{*}{$\begin{array}{l}\text { Type of } \\
\text { study }\end{array}$} & \multirow[b]{2}{*}{ Comments } \\
\hline & Number & Age & & \\
\hline Cavanna et al. ${ }^{1}$ & N/A & N/A & Review & $\begin{array}{l}\text { The prevalence of neuropsychiatric comorbidities in TS is } 90 \% \text { and } \\
\text { ADHD and OCD are the most common. The former is found in } 60 \text { to } \\
80 \% \text {, and the latter, in } 11 \text { to } 80 \% \text { of patients with TS. Depression, } \\
\text { followed by personality disorders, is also common in TS. }\end{array}$ \\
\hline Du et al. ${ }^{2}$ & $\mathrm{~N} / \mathrm{A}$ & N/A & Review & $\begin{array}{l}\text { In an epidemiological study, ADHD was the most common } \\
\text { comorbidity in children aged } 6 \text { to } 12 \text { years. Other behavior } \\
\text { disorders, OCD, other anxiety disorders and learning disabilities } \\
\text { are also common. }\end{array}$ \\
\hline Cavanna et al. ${ }^{14}$ & 102 & $\begin{array}{l}\geq 16 \\
\text { years }\end{array}$ & $\begin{array}{l}\text { Descriptive } \\
\text { study, } \\
\text { signs and } \\
\text { symptoms }\end{array}$ & $\begin{array}{l}\text { Anxiety disorders are the most common comorbidities in this } \\
\text { study of patients with TS. The second major comorbidity is ADHD. } \\
\text { Obsessive-compulsive disorder and mood disorders are also very } \\
\text { prevalent. }\end{array}$ \\
\hline Coffey et al. ${ }^{15}$ & 190 & Unknown & $\begin{array}{l}\text { Descriptive } \\
\text { study, } \\
\text { signs and } \\
\text { symptoms }\end{array}$ & $\begin{array}{l}\text { Psychiatric comorbidities are found in almost all patients with TS. } \\
\text { ADHD and behavior disorders in general were the most prevalent } \\
\text { comorbidities. Mood disorders and anxiety disorders are also very } \\
\text { prevalent. }\end{array}$ \\
\hline Comings $^{16}$ & N/A & N/A & Review & $\begin{array}{l}\text { The most common comorbidities in this review are ADHD, other } \\
\text { behavior disorders, and disorders of the obsessive-compulsive } \\
\text { spectrum. Sleep disorders and learning disabilities are common. }\end{array}$ \\
\hline Fernández-Alvarez et al. ${ }^{17}$ & 340 & Unknown & $\begin{array}{l}\text { Review } \\
\text { Descriptive } \\
\text { study, } \\
\text { signs and } \\
\text { symptoms }\end{array}$ & $\begin{array}{l}\text { For all patients with tics and TS, OCD is the most prevalent } \\
\text { comorbidity, although the difference from ADHD is not great. }\end{array}$ \\
\hline Kano et al. ${ }^{18}$ & 88 & $\begin{array}{l}\text { Mean: } \\
15.2\end{array}$ & $\begin{array}{l}\text { Review } \\
\text { Descriptive } \\
\text { study, } \\
\text { signs and } \\
\text { symptoms }\end{array}$ & $\begin{array}{l}\mathrm{OCD} \text { is the most common comorbidity in patients with TS, at a } \\
\text { prevalence of } 41.6 \% \text {. ADHD was found in } 29.2 \% \text { of the patients. }\end{array}$ \\
\hline
\end{tabular}

$\mathrm{ADHD}=$ attention deficit hyperactivity disorder; N/A = not applicable; OCD = obsessive-compulsive disorder; TS = Tourette's syndrome. 
Table 2 - Summary of main psychiatric comorbidities of Tourette's syndrome

\begin{tabular}{lc}
\hline Comorbidities & Prevalence (\%) \\
\hline Overall, mean & 90 \\
Attention deficit hyperactivity disorder & $40-80$ \\
Disruptive behavior disorders & $30-90$ \\
Learning disabilities, mean & 22.7 \\
Obsessive-compulsive disorder & $11-80$ \\
Other anxiety disorders, mean & 40 \\
Mood disorders & $13-76$ \\
Major depressive disorder & $49-59$ \\
Bipolar disorder & $14-29$ \\
Sleep disorders & $20-45$ \\
Personality disorders & $15-64$ \\
Pervasive developmental disorders & $16-30$ \\
\hline
\end{tabular}

Data express range, unless otherwise stated.

ADHD and related disorders are classified as the most common comorbidities in TS. OCD is the second most common comorbidity in a group with other anxiety disorders. However, OCD also includes patients whose clinical features are not linked to TS.

Mood disorders are the third most prevalent comorbidities, followed by sleep and personality disorders. The next group includes pervasive developmental disorders, and the last one, called other comorbidities, includes other pathologies not analyzed in the comparative studies included in this review and, therefore, only discussed in a few studies.

\section{ADHD, other behavior disorders and learning disabilities}

This group includes some of the disorders usually diagnosed during early and late childhood. Both TS and ADHD are associated with deficient performance on visual-motor integration tasks when compared with normal controls. These findings helped identify the basal ganglia and fronto-corticoestriate circuits as the neuroanatomical region of interest in TS research. They also suggested similar explanations for the pathogenesis of ADHD, as the prevalence of ADHD in TS is high. ${ }^{19,20}$

ADHD is a polygenic disorder associated with the additive effect of genes affecting $D A, N E$, serotonin, GABA, and other neurotransmitters. This model is consistent with all current knowledge about ADHD, including the increased frequency of $A D H D$ among relatives of probands with $A D H D$, the failure to explain this as the result of any single neurotransmitter defect and its close association with TS. ${ }^{16}$

Attention deficit disorder (ADD) with or without hyperactivity is found in $49 \%$ to $83 \%$ of patients with TS. Up to $50 \%$ of all children with ADHD have a history of tics, which suggests that ADHD and TS are genetically related in many cases, and that ADHD may be part of the pleiotropic gene expression of TS. ${ }^{21}$ The 1 allele of the DA D2 receptor (D2A1) was found in patients with ADHD and autism, and the association of these disorders with TS may suggest that these entities are genetically interrelated.

However, Stewart et al. ${ }^{22}$ suggested that TS and ADHD are not always etiologically linked, and $O C D$, particularly in cases of early onset, seems to play an important role in the coexistence of TS and ADHD (TS+ADHD), with a higher prevalence of $O C D$ in these patients.

Yordanova et al. ${ }^{23}$ analyzed event-related electroencephalographic (EEG) oscillations in the theta frequency band to elucidate the neurophysiological background of TS+ADHD. Early theta response was specifically enhanced only in TS+ADHD, supporting the interactive model in the neurocognitive domain and suggesting that this comorbidity may be classified at several levels, from neurobiological to neurophysiological.

According to Sukhodolsky et al., ${ }^{19}$ the dysfunction in the basal ganglia and thalamus, responsible for the genesis of tics, may lead to the emergence of abnormal arrhythmic activity in cortical regions into which the pathways involved in motor inhibition and cognitive control are projected. Therefore, this abnormal activity may be associated with ADHD secondary to TS.

Clinical features of TS and ADHD improves as children grow up, as seen in $40 \%$ of children with ADHD and in $80 \%$ of those with TS when they reach adolescence. This improvement may be the result of a greater functional capacity of the frontal cortical regions due to more myelination, which increases the number of inhibitory interneurons. Successful compensatory mobilization of prefrontal areas involved in response inhibition may play a role in the reduction of tics and ADHD symptoms by early adulthood.

Ludolph et al. ${ }^{24}$ found that the volume of the amygdala in the left hemisphere of patients with TS was lower than in the control group. This difference was not associated with tic severity, but with the coexistence of ADHD symptoms, which may be explained as a dysfunction of the amygdala input to the striatum and frontal cortex. In an experimental study, Nordstrom et al. ${ }^{25}$ found that the hypoactivity of glutamatergic efferent cortical-limbic pathways leads to ADHD.

Immune-based theories for the causes of TS have been described as well. Antibodies to group A betahemolytic streptococcal infections may cross-react with proteins in basal ganglia regions of the brain to produce tics or psychiatric symptoms, a syndrome called pediatric 
autoimmune neuropsychiatric disorders associated with streptococcal infections (PANDAS). ${ }^{10}$ Peterson et al. ${ }^{26}$ found a positive correlation between ADHD and antistreptococcal antibody titers.

Lit et al. ${ }^{10}$ used genomic profiling of peripheral blood because TS may have genetic as well as autoimmune causes. Their study identified a subgroup of patients with heritable TS and a specific phenotype of gene expression in blood and drew attention to natural killer (NK) cytotoxicity and antigen presentation. An association with ADHD was found in this subgroup, which confirms the possibility of a convergent pathway that contributes to both TS and ADHD (NK dysregulation, ADHD and TS). NK cells are key components of innate immunity, as they are primarily activated in response to infections and cell changes. The association between NK cells and autoimmunity is intriguing, and further studies are needed to clarify their contribution, as well as that of immunity in general, to the pathogenesis of TS.

Although multiple lines of evidence suggest that both genetic and environmental factors contribute to TS, the potential role of environmental factors has been less studied. Mathews et al. ${ }^{27}$ investigated whether and how adverse prenatal and perinatal events might explain TS and its comorbidities. Their study found that the number (but not the type) of prenatal problems and lower birth weight were associated with an increased risk of comorbid ADHD, which confirms that TS and its comorbidities are neurodevelopmental disorders.

Finally, a question has raised some controversy: whether the coexistence of tics and ADHD results from the medication used to treat hyperactivity. However, most anti-hyperactivity medications do not increase the likelihood to develop tics or worsen their severity. Indeed, alpha-2 agonists and atomoxetine seem to reduce tics. Nevertheless, dexamphetamine may be associated with tics at doses above those regarded as therapeutic. ${ }^{28}$

In addition to ADHD, other behavior disorders have been associated with TS. Budman et al. ${ }^{29}$ reported that $50 \%$ of the children with TS, ADHD and OCD have disruptive behavior disorders. There is considerable evidence of the role of serotonergic, noradrenergic and dopaminergic neurotransmission in aggressive behaviors and, therefore, the association between these disorders may be explained. Several studies ${ }^{4,28}$ have found that numerous behavior (disruptive) disorders in children with TS are, indeed, due to ADHD and not to TS, even in the presence of severe tics.

Learning disabilities are a common disorder also linked to TS. $^{30}$ According to some studies, learning disabilities associated with academic skills are more closely linked to ADHD. ${ }^{31,32}$ In contrast, learning procedures (motor skills) are associated with TS. ${ }^{33}$

\section{OCD and other anxiety disorders}

Some authors have reported that the co-occurrence of TS and OCD is common and found in $40 \%$ to $75 \%$ of the cases. ${ }^{34}$ Mathias et al. ${ }^{35}$ found that $37.5 \%$ of patients with early-onset OCD (onset < 11 years) had comorbid tic disorders, and the prevalence of tics in both earlyand late-onset OCD was $29 \%$. Jaisoorya et al. ${ }^{36}$ found a male preponderance in patients with TS+OCD.

One of the features that these pathologies may share is the sensory phenomenon, a bodily (tactile and/or musculoskeletal and visceral) or mental (e.g., innertension, feeling of imperfection) sensation that precedes the repetitive behavior, usually disappearing after performing it. This feature is similar to obsessive symptoms, which only cease when the compulsive behavior is completed. Miguel et al. ${ }^{37}$ analyzed the concept of sensory phenomena in patients with TS, OCD and TS+OCD and found that the presence of sensory phenomena is more common in patients with TS or TS+OCD. These results are similar to those found by Leckman et al. ${ }^{8}$ However, sensory phenomena and obsessions are not exactly the same, as we illustrate in Figure 2.

Alvarenga et al. $^{38}$ noted that TS+OCD patients were more likely to be boys, to experience sensory phenomena and have comorbid anxiety disorders in general and ADHD. Additionally, the aggressive, sexual/ religious and hoarding symptom dimensions were more severe in that group, which may be explained

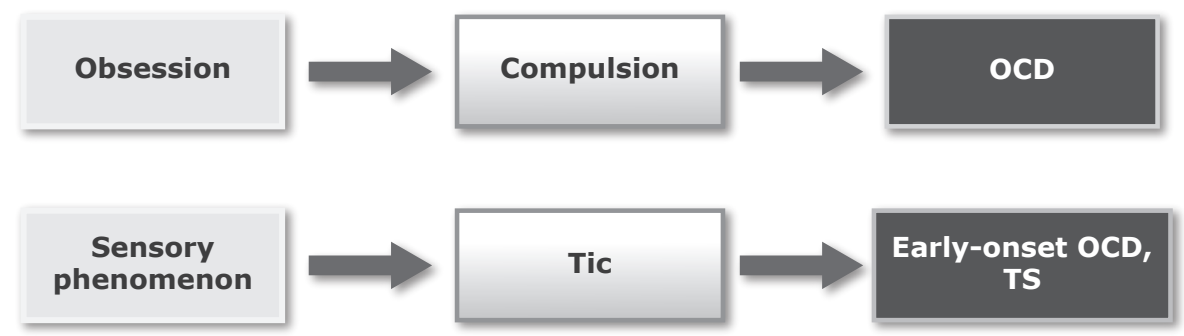

Figure 2 - Schematic illustration of the difference between obsession and sensory phenomenon. The association between obsession and compulsion may be compared with that between sensory phenomenon and tic. Sensory phenomena are more common in patients with Tourette's syndrome (TS) and early-onset obsessive-compulsive disorder (OCD). 
by abnormalities in serotonin pathways in the case of OCD alone and in the dopaminergic and serotoninergic pathways in the TS+OCD group. In fact, several studies $^{39-41}$ have demonstrated that the DA and serotonin neurotransmitters are involved in the etiopathogenesis of TS+OCD. Because of that, several authors have tried to define early- and late-onset OCD. Nevertheless, the cutoff points are not the same in different studies. $25,35,42,43$

The etiopathogenesis of TS+OCD is not fully understood. Bolton et al. ${ }^{44}$ studied monozygotic and dizygotic twins and found that there is a genetic substrate, although genetic factors do not fully explain the co-occurrence of TS+OCD.

Most chromosomal karyotypes in patients with TS are normal, and, therefore, there is no reason for standard chromosomal examinations. However, when other clinical abnormalities, in addition to TS, are identified, a chromosomal analysis should often be conducted. Verkerk et al. ${ }^{45}$ studied a family in which the father had TS+OCD, the mother was normal and the two children had TS+OCD and mental and growth retardation. The father and the two children had in common a complex chromosomal insertion/translocation involving chromosomes 2 and 7: they shared an insertion of 2p21-p23 on chromosome 7q35-q36. The pathologies that they all shared were TS and OCD, and, therefore, this gene seems to be responsible for the co-occurrence of TS+OCD in these patients. The coexistence of mental and growth retardation in the children might be explained by other chromosomal abnormalities that the children, but not the father, had. That insertion into chromosome 7 interrupts the contactin-associated protein 2 gene (CNTNAP2). Although its function has not been clearly defined, the disruption or decreased expression of CNTNAP2 might lead to a disturbed distribution of the juxtaparanodal clustering of Shaker-like $\mathrm{K}^{+}$channels in the nervous system and affect conduction and repolarization, which, as a result, leads to the movements seen in TS. Cuker et al. ${ }^{46}$ described the case of a 14 -year-old girl with severe OCD who had the following translocation: $t_{(2 ; 18)(p 12, q 22)}$. The chromosome 18 breakpoint (a relatively gene-poor region) had already been identified in two other cases, one of them with TS+OCD and the other with chronic tic disorder and OCD. These findings suggest that the noncoding regions should be explored.

Immune-based theories have also been postulated. Peterson et al. ${ }^{26}$ found that in patients with ADHD, OCD or both disorders higher antistreptococcal antibody titers were associated with structural alterations in basal ganglia. They suggested that, when there was host susceptibility to autoimmune disorders, an infection by group $A \beta$-hemolytic streptococcus (GABHS) produces GABHS antibodies that cross-react with and presumably compromise neural proteins, which may lead to different psychopathologies depending on the structures that are affected.

In an attempt to understand the differences in volume of the basal ganglia in children and adults with TS and their association with comorbidities, Peterson et al. ${ }^{47}$ used high-resolution magnetic resonance to measure basal ganglia volume. They found that adults with TS and children with TS+OCD had smaller lenticular nucleus volumes and concluded that this is a marker of comorbid OCD and persistence of tics in adulthood.

The role of glutamate, in addition to that of serotonin and DA, in patients with TS+OCD has also been studied. ${ }^{25,34}$

Some hormones seem to play a role in the cooccurrence of TS+OCD. The onset and recurrence of TS have been associated with significant emotional contexts. Chappell et al. ${ }^{7}$ measured the central activity of corticotropin releasing factor (CRF) in patients with TS+OCD and found that the levels in lumbar cerebrospinal fluid were moderately higher, but statistically significant, than in both normal controls and patients with OCD, which suggests that these patients are more sensitive to lower levels of stress. Leckman et al. ${ }^{8}$ studied the role of oxytocin and vasopressin and found that high levels of oxytocin were not associated with TS, but with OCD alone. This suggests that OCD has different etiopathogenesis and clinical features.

Finally, as seen in ADHD, environmental factors seem to be important to understand at least some cases of OCD. Mathews et al. ${ }^{27}$ found that prenatal maternal smoking was strongly correlated with increased tic severity and comorbid OCD in TS. Basal ganglia are sensitive to hypoxia, an important marker of fetal distress that may affect the expression of genes and increase the risk of developing TS. Fetal hypoxia secondary to chronic nicotine exposure may increase the severity of tics as well as the risk of developing OCD.

In addition to OCD, all anxiety disorders, especially separation anxiety, were significantly associated with tic severity in patients with TS or TS+OCD+ADHD. ${ }^{15,48}$ The association with anxiety disorders may have different reasons: tics improve with anxiolytic medication and worsen when children return to school (a stress factor) ${ }^{15}$; neuroleptics may cause anxiety as an adverse reaction, which initiates or worsens tics; and comorbidities, such as ADHD, lead to anxiety disorders. ${ }^{11}$ The hyperresponsiveness of the hypothalamic-pituitary axis may also explain the anxiety disorders found in TS.

Here there is a vicious cycle: anxiety worsens tics and tics increase anxiety symptoms. Furthermore, Cohen et al. ${ }^{11}$ concluded that the presence of obsessive-compulsive symptoms increases the prevalence and severity of other anxiety disorders. Undoubtedly, severity is positively 
correlated with the number of comorbidities. In addition to that, psychosocial factors are also very important, as an external locus of control (LOC) is associated with an increased risk of anxiety disorders. ${ }^{11}$

\section{Mood disorders}

Major depressive disorder is the most common complication of OCD, with a prevalence ranging from 13 to $75 \%$, which is relevant because OCD is one of the most important comorbidities of TS. Depression is often associated with increased severity of tics, sleep disorders and ADHD. ${ }^{12}$

Etiopathogenesis is multifactorial. Robertson et al. ${ }^{49}$ found that children with TS had more depressive symptoms than controls. However, depressive symptoms are not enough to establish a major depressive disorder diagnosis. They concluded that the greater number of depressive symptoms might be explained by environmental and social factors. Figure 3 shows the etiologic factors of depression.

According to some studies, ${ }^{50}$ the lifetime prevalence of bipolar disorder is $5 \%$, and $19.1 \%$ of patients with TS have mania. Kerbeshian et al. ${ }^{51}$ concluded that the risk of developing bipolar disorder in children, adolescents and adults with TS is four times greater than what would be expected by chance; moreover, the risk is higher for boys.

Berthier et al. ${ }^{52}$ found that bipolar disorder in patients with TS is associated with other comorbidities, such as OCD, generalized anxiety disorder, eating disorders, panic disorder, social phobia and ADHD. Interestingly, in their study, all patients had a personality disorder. These findings confirm that numerous psychiatric disorders are commonly found in patients with TS. Some authors ${ }^{15}$ suggested that some aggressive and impulsive behaviors observed in children with TS might be underdiagnosed bipolar disorder.

The etiopathogenesis of this comorbidity is unknown. Bipolar disorder in TS may result from a dysfunction of the DA, NE and serotonin neurotransmitters or, in other cases, an adverse drug reaction associated with the psychostimulants used to treat the comorbid ADHD. ${ }^{12}$ Berthier et al. ${ }^{52}$ identified a dysfunction of the relation between the extrapyramidal and the limbic systems. In fact, manic episodes are observed in other pathologies that involve subcortical structures, such as Huntington's disease.

\section{Sleep disorders}

Sleep disorders are also common. Robertson et al. ${ }^{49}$ reported that, in a study of young people with TS, $26 \%$ had nightmares and $33 \%$ had sleepwalking. According to the same authors, these parasomnias have a similar prevalence in adult patients with TS.

Their etiology seems multifactorial. In ADHD, commonly associated with sleep disorders, there is initial insomnia, sleepwalking and hypersomnia. ${ }^{28}$ In a study conducted by Kirov et al.,53 ADHD and TS were characterized by prominent and specific changes in polysomnographic parameters indicating that the neural substrates of ADHD and TS are involved in sleep regulation dissimilarly. ADHD was primarily characterized by an increase in rapid eye movement sleep, whereas patients with TS displayed poorer sleep efficiency and elevated arousal index during sleep. In the patients with ADHD+TS, both ADHD- and TS-related changes in sleep persist independently, and no sleep alterations specific for comorbidity were found. Consequently, coexisting ADHD and TS may be a combination of two independent pathologies, and, therefore, TS and its comorbidities may lead to sleep disorders.

Depressive symptoms lead to sleep disorders ${ }^{12}$; and sleep disorders may result from anxiety disorders, particularly separation anxiety.

The role of genetic factors has also been studied. Some authors found a variant of orexin genes, which have been shown to be essential for normal sleep in patients with TS+ADHD. ${ }^{54}$

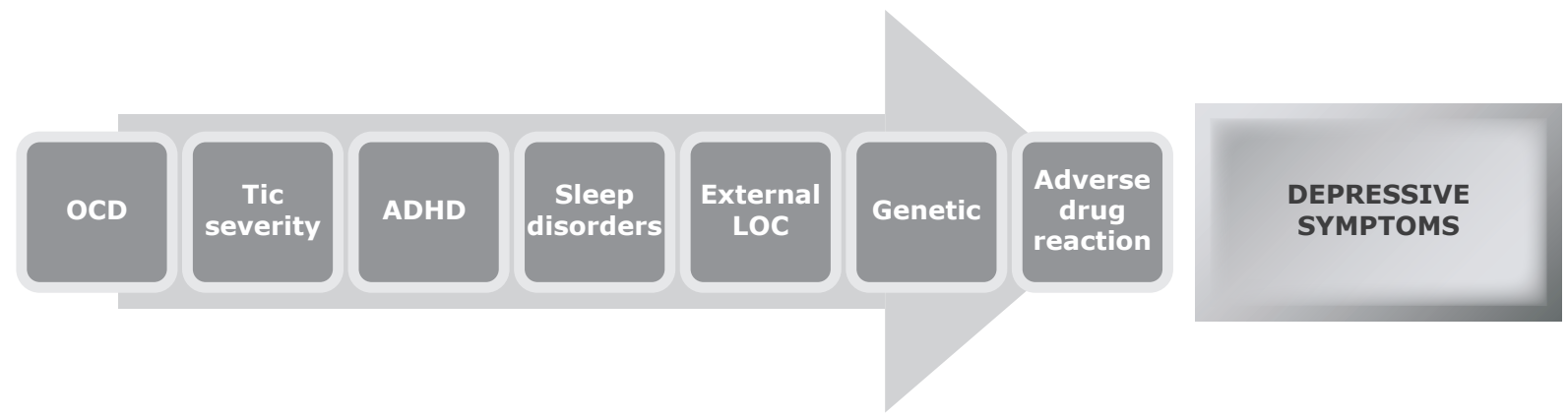

Figure 3 - Schematic illustration of the etiology of depression in Tourette's syndrome (TS). Depressive symptoms in patients with TS often result from tic severity and neuropsychiatric comorbidities, particularly obsessive-compulsive disorder (OCD) and attention deficit hyperactivity disorder (ADHD). Other factors, such as external locus of control (LOC), are also important. 
Finally, According to Taylor et al., ${ }^{28}$ some cases of insomnia may be assigned to the use of psychostimulants.

\section{Personality disorders}

Several personality disorders are found in TS, at a higher prevalence than in the general population, ${ }^{14,39,52}$ which may be explained by several factors. The obsessive-compulsive personality is a risk factor for the development of $O C D$, one of the most prevalent psychiatric disorders in patients with TS. The prevalence of avoidant and dependent personalities is associated with the high prevalence of anxiety disorders in TS. Paranoid and schizotypal personalities may result from the worry of expressing tics and being seen and criticized or rejected by others. ${ }^{14}$ Patients with a schizoid personality may be those at a greater risk of pervasive developmental disorders. Finally, borderline personalities are associated with mood disorders.

\section{Pervasive developmental disorders}

Pervasive developmental disorders, common in TS, are neurodevelopmental disorders. ${ }^{55,56}$ Baron-Cohen et al. ${ }^{57}$ found that, although distinct, autism and TS share several behavioral features, such as echolalia and palilalia, as well as obsessive-compulsive symptoms. Autism and TS have abnormal motor behaviors, although in autism they are stereotypes and may, occasionally, be difficult to distinguish from complex motor tics.

Zappella $^{58}$ described comorbidity with reversible autistic behavior and also found that boys were more affected and comorbidity with ADHD was prevalent. Symptoms of autism spectrum disorders are also common in other TS comorbidities, such as OCD. ${ }^{59}$

\section{Other comorbidities}

Other pathologies may be found in patients with tics. The presence of schizophrenia in TS is intriguing. The prevalence of childhood-onset schizophrenia is rare: one to two cases per 100,000 . However, the prevalence of schizophrenia in children with TS between two and twelve years is about $8.7 \%$, and boys are also more affected. Furthermore, childhood-onset schizophrenia is associated with more comorbidities, especially ADHD and OCD, than schizophrenia with an adolescent- or adultonset. ${ }^{60}$ This fact reinforces the idea that TS and the associated disorders may result from a neurobiological vulnerability to aggressive factors during the critical periods of development. A functional disturbance of the dopaminergic neurotransmission from the basal ganglia to the limbic and frontal cortex areas may be a biological correlate of both schizophrenia and TS. Interestingly, there is growing evidence that inflammatory or immune processes, such as the increase of antibodies against heat-shock protein, play a role in the pathogenesis of at least a subgroup of patients with schizophrenia and are characterized by negative symptoms. This subgroup may also have an increased risk of comorbidity with TS. ${ }^{61}$

The frequency of migraine in patients with TS is four-fold greater than in the general population, which indicates that migraine is an important TS comorbidity. ${ }^{62,63}$ That may result from a disturbance in the basal gangliathalamocortical circuitry. The basal ganglia are actively involved in the modulation of pain and nociceptive sensorimotor integration and provide a coordinated response to damaging or potentially damaging stimuli (escape behavior). Therefore, the high frequency of migraine in TS may result from a disturbance of the more general role of the extrapyramidal system in the processing of nociceptive information. Serotonin may also play a role in explaining migraine, TS, OCD and mood disorders. ${ }^{62}$ Moreover, as in TS, migraine may be triggered by intense stimuli or stress. The CRF-ACTHcortisol axis, which seems to be hyperresponsiveness in patients with TS, also contributes to escape behavior and may be shared by migraine.

Some chromosome disorders, such as Down and Fragile $X$ syndromes, have been found in patients with TS that had other comorbidities, namely ADHD and other behavior disorders, OCD and autism. Boys seem to be more affected and, therefore, the role of the $X$ chromosome was analyzed. However, the relevance of these comorbidities remains controversial. ${ }^{64,65}$ Also, a patient with Diogenes syndrome, OCD and TS has been described, but the exact nature of how these disorders may be associated remains to be determined. ${ }^{66}$

Other authors ${ }^{67}$ described a patient with frontotemporal dementia who developed complex motor and vocal tics similar to those of TS. That reinforces the role of the frontal cortex in TS.

Some patients develop TS after an infection, and the confirmation of streptococcal infection, Lyme disease and, more recently, mycoplasma pneumoniae in patients with TS suggests that infection or the post-infectious immune process may play a role in the pathogenesis of TS. ${ }^{68}$

\section{Discussion and conclusions}

Several neuropsychiatric comorbidities are found in patients with tics, particularly in TS, and, therefore, the clinical features of patients with TS may vary substantially.

The study of comorbidities may clarify the boundaries of some psychiatric disorders, and this review contributes to that. OCD is a good example: although all patients have intrusive thoughts that they try to 
counteract by performing compulsions, the analysis of the obsessive-compulsive symptoms or the age at which they began reveals that this disorder affects patients with particular clinical features and comorbidities, and an etiopathogenesis that has its own subtleties. In fact, early-onset OCD was different from OCD alone and it was associated with TS.

TS and its associated disorders are more common in boys and, therefore, hormones, particularly androgens, may play a role in TS and its comorbidities. For instance, some patients with TS have a borderline personality associated with unstable or absent gender identity. ${ }^{69}$ Clinical studies should be designed to conduct a profound analysis of the influence of a disturbed androgen metabolism on psychopathology.

Of all TS comorbidities, ADHD and other behavioral disorders are the most prevalent. The role of innate and adaptive immunity should be considered, as NK cells and antibodies to group A beta-hemolytic streptococcal infections are associated with the etiopathogenesis of ADHD+TS. In addition to genetic factors, the role of the environment should be investigated, as there is a positive correlation between adverse prenatal events and ADHD. Moreover, fetal hypoxia secondary to chronic nicotine exposure might increase the severity of tics, as well as the risk of developing early-onset OCD. The impact of exogenous stress factors on a vulnerable biological substrate during the critical periods of neurodevelopment may be important in the etiopathogenesis of other neuropsychiatric disorders. Therefore, the association between those factors and other neuropsychiatric disorders seen in TS should be studied. Particularly, the types of exogenous stress factors that play a more relevant role should be described. In fact, patients with TS have a hyperresponsiveness to the CRF-ACTH-cortisol axis, which is associated with stress response, and tics worsen with psychosocial factors (stress factors). Interestingly, there is a positive correlation between antibodies against heat-shock proteins, characteristic of cellular stress response, and patients with schizophrenia and comorbid TS. The same findings may be found in patients with TS and other associated disorders. Further studies are needed to clarify whether or not there is a positive correlation between antibodies against heatshock proteins and patients with TS patients and, in the same line of thought, whether that correlation is found in patients with TS and other comorbidities as well. To sum up, there is growing evidence that inflammatory responses, associated with stress factors, and immune processes may be important in the pathogenesis of TS and its comorbidities.

ADHD and OCD are the most common comorbidities and, therefore, the ones most often described. However, other comorbidities also have a high prevalence. Sleep disturbances are common in ADHD and, given the high prevalence of ADHD in patients with TS, sleep disorders are also prevalent in TS. In contrast, depressive symptoms and anxiety disorders are common in patients with TS, and these symptoms contribute to the high prevalence of sleep disorders. The etiology of mood disorders is multifactorial and includes psychosocial factors, such as LOC, and these important factors should be considered when defining the treatment of patients with TS. For instance, depressive symptoms may result from the rejection by others because of the harmful impact of tics on interpersonal relationships, and this rejection may explain other associated disorders, such as separation anxiety and some personality disorders.

In conclusion, in addition to tics, the analysis of patients with TS should include all these prevalent comorbidities, so that the best treatment is chosen for each case. Furthermore, as TS is in the interface between Psychiatry and Neurology and has several psychiatric comorbidities, the study of this syndrome may contribute to the understanding of several neuropsychiatric pathologies.

\section{Acknowledgements}

We thank Helena Donato for her help with the systematic review using the $5 \mathrm{~S}$ levels of evidence described by Haynes.

\section{References}

1. Cavanna AE, Servo S, Monaco F, Robertson MM. The behavioral spectrum of Gilles de la Tourette syndrome. J Neuropsychiatry Clin Neurosci. 2009;21:13-23.

2. Du JC, Chiu TF, Lee KM, Wu HL, Yang YC, Hsu SY, et al. Tourette syndrome in children: an updated review. Pediatr Neonatol. 2010;51:255-64.

3. Jankovic J. Tourette's syndrome. N Engl J Med. 2001;345:1184-92.

4. Sukhodolsky DG, Scahill L, Zhang $H$, Peterson BS, King RA, Lombroso PJ, et al. Disruptive behavior in children with Tourette's syndrome: association with ADHD comorbidity, tic severity, and functional impairment. J Am Acad Child Adolesc Psychiatry. 2003;42:98-105.

5. Robertson MM. The prevalence and epidemiology of Gilles de la Tourette syndrome. Part 1: the epidemiological and prevalence studies. J Psychosom Res. 2008;65:461-72. Epub 2008 Oct 2.

6. Robertson MM. The prevalence and epidemiology of Gilles de la Tourette syndrome. Part 2: tentative explanations for differing prevalence figures in GTS, including the possible effects of psychopathology, aetiology, cultural differences, and differing phenotypes. J Psychosom Res. 2008;65:473-86. Epub 2008 Oct 2.

7. Chappell P, Leckman J, Goodman W, Bissette G, Pauls D, Anderson $\mathrm{G}$, et al. Elevated cerebrospinal fluid corticotropin-releasing factor in Tourette's syndrome: comparison to obsessive compulsive disorder and normal controls. Biol Psychiatry. 1996;39:776-83.

8. Leckman JF, Goodman WK, North WG, Chappell PB, Price $\mathrm{LH}$, Pauls $\mathrm{DL}$, et al. Elevated cerebrospinal fluid levels of oxytocin in obsessive-compulsive disorder. Comparison with Tourette's syndrome and healthy controls. Arch Gen Psychiatry. 1994;51:782-92.

9. Alexander GM, Peterson BS. Testing the prenatal hormone hypothesis of tic-related disorders: gender identity and gender role behavior. Dev Psychopathol. 2004;16:407-20. 
10. Lit L, Gilbert DL, Walker W, Sharp FR. A subgroup of Tourette's patients overexpress specific natural killer cell genes in blood: a preliminary report. Am J Med Genet B Neuropsychiatr Genet. 2007; 144B:958-63.

11. Cohen E, Sade M, Benarroch F, Pollak Y, Gross-Tsur V. Locus of control, perceived parenting style, and symptoms of anxiety and depression in children with Tourette's syndrome. Eur Child Adolesc Psychiatry. 2008;17:299-305. Epub 2008 Feb 26.

12. Robertson MM. Mood disorders and Gilles de la Tourette's syndrome: An update on prevalence, etiology, comorbidity, clinical associations, and implications. J Psychosom Res. 2006;61:34958.

13. Haynes RB. Of studies, syntheses, synopses, summaries, and systems: the " $5 \mathrm{~S}$ " evolution of information services for evidencebased healthcare decisions. Evid Based Med. 2006;11:162-4.

14. Cavanna AE, Robertson MM, Critchley HD. Schizotypal personality traits in Gilles de la Tourette syndrome. Acta Neurol Scand. 2007;116:385-91.

15. Coffey BJ, Biederman J, Smoller JW, Geller DA, Sarin P, Schwartz $S$, et al. Anxiety disorders and tic severity in juveniles with Tourette's disorder. J Am Acad Child Adolesc Psychiatry. 2000;39:562-8.

16. Comings DE. Clinical and molecular genetics of ADHD and Tourette syndrome. Two related polygenic disorders. Ann N Y Acad Sci. 2001;931:50-83.

17. Fernández-Alvarez E. [Comorbid disorders associated with tics]. Rev Neurol. 2002;34 Suppl 1:S122-9.

18. Kano Y, Ohta M, Nagai Y, Scahill L. Association between Tourette syndrome and comorbidities in Japan. Brain Dev. 2010;32:201-7. Epub 2009 Feb 28.

19. Sukhodolsky DG, Leckman JF, Rothenberger A, Scahill L. The role of abnormal neural oscillations in the pathophysiology of cooccurring Tourette syndrome and attention-deficit/hyperactivity disorder. Eur Child Adolesc Psychiatry. 2007;16 Suppl 1:51-9.

20. Pascual-Castroviejo I. [Comorbid disorders of the attention deficit with hyperactivity disorder]. Rev Neurol. 2002;35:11-7.

21. Knell ER, Comings DE. Tourette's syndrome and attention-deficit hyperactivity disorder: evidence for a genetic relationship. J Clin Psychiatry. 1993;54:331-7.

22. Stewart SE, Illmann C, Geller DA, Leckman JF, King R, Pauls DL. A controlled family study of attention-deficit/hyperactivity disorder and Tourette's disorder. J Am Acad Child Adolesc Psychiatry. 2006;45:1354-62.

23. Yordanova J, Heinrich $H$, Kolev $V$, Rothenberger A. Increased event-related theta activity as a psychophysiological marker of comorbidity in children with tics and attention-deficit/ hyperactivity disorders. Neuroimage. 2006;32:940-55. Epub 2006 May 26.

24. Ludolph AG, Pinkhardt EH, Tebartz van Elst L, Libal G, Ludolph AC, Fegert JM, et al. Are amygdalar volume alterations in children with Tourette syndrome due to ADHD comorbidity? Dev Med Child Neurol. 2008;50:524-9.

25. Nordstrom EJ, Burton FH. A transgenic model of comorbid Tourette's syndrome and obsessive-compulsive disorder circuitry. Mol Psychiatry. 2002; 7:617-25, 524.

26. Peterson BS, Leckman JF, Tucker D, Scahill L, Staib L, Zhang $H$, et al. Preliminary findings of antistreptococcal antibody titers and basal ganglia volumes in tic, obsessive-compulsive, and attention deficit/hyperactivity disorders. Arch Gen Psychiatry. 2000;57:364-72.

27. Mathews $C A$, Bimson $B$, Lowe $T L$, Herrera LD, Budman $C L$, Erenberg G, et al. Association between maternal smoking and increased symptom severity in Tourette's syndrome. Am J Psychiatry. 2006;163:1066-73.

28. Taylor E. Sleep and tics: problems associated with ADHD. J Am Acad Child Adolesc Psychiatry. 2009;48:877-8.

29. Budman CL, Bruun RD, Park KS, Olson ME. Rage attacks in children and adolescents with Tourette's disorder: a pilot study. J Clin Psychiatry. 1998;59:576-80.

30. Steinberg T, Tamir I, Zimmerman-Brenner S, Friling M, Apter A. Prevalence and comorbidity of tic disorder in Israeli adolescents: results from a national mental health survey. Isr Med Assoc ]. 2013;15:94-8

31. Walkup JT, Scahill LD, Riddle MA. Disruptive behaviour, hyperactivity, and learning disabilities in children with Tourette's syndrome. Adv Neurol. 1995;65:259-72.

32. Burd L, Freeman RD, Klug MG, Kerbeshian J. Tourette Syndrome and learning disabilities. BMC Pediatr. 2005;5:34.

33. Marsh R, Alexander GM, Packard MG, Zhu H, Wingard JC, Quackenbush G, et al. Habit learning in Tourette syndrome: a translational neuroscience approach to a developmental psychopathology. Arch Gen Psychiatry. 2004;61:1259-68.

34. McGrath MJ, Campbell KM, Parks CR, Burton FH. Glutamatergic drugs exacerbate symptomatic behavior in a transgenic model of comorbid Tourette's syndrome and obsessive-compulsive disorder. Brain Res. 2000;15;877:23-30.

35. de Mathis MA, Diniz JB, Shavitt RG, Torres AR, Ferrão YA, Fossaluza V, et al. Early onset obsessive-compulsive disorder with and without tics. CNS Spectr. 2009;14:362-70.

36. Jaisoorya TS, Reddy YC, Srinath S, Thennarasu K. Obsessivecompulsive disorder with and without tic disorder: a comparative study from India. CNS Spectr. 2008;13:705-11.

37. Miguel EC, do Rosário-Campos MC, Prado HS, do Valle R, Rauch SL, Coffey BJ, et al. Sensory phenomena in obsessive-compulsive disorder and Tourette's disorder. J Clin Psychiatry. 2000;61:1506; quiz 157.

38. Gomes de Alvarenga $P$, de Mathis MA, Dominguez Alves AC, do Rosário MC, Fossaluza V, Hounie AG, et al. Clinical features of tic-related obsessive-compulsive disorder: results from a large multicenter study. CNS Spectr. 2012;17:87-93.

39. Hemmings SM, Kinnear CJ, Lochner C, Niehaus DJ, Knowles JA, Moolman-Smook JC, et al. Early- versus late-onset obsessivecompulsive disorder: investigating genetic and clinical correlates. Psychiatry Res. 2004;128:175-82.

40. Bloch MH, Landeros-Weisenberger A, Sen S, Dombrowski P, Kelmendi $\mathrm{B}$, Coric $\mathrm{V}$, et al. Association of the serotonin transporter polymorphism and obsessive-compulsive disorder: systematic review. Am J Med Genet B Neuropsychiatr Genet. 2008;147B:850-8.

41. Müller-Vahl KR, Meyer GJ, Knapp WH, Emrich HM, Gielow $P$, Brücke $T$, et al. Serotonin transporter binding in Tourette Syndrome. Neurosci Lett. 2005;385:120-5.

42. Janowitz D, Grabe HJ, Ruhrmann S, Ettelt S, Buhtz F, Hochrein A, et al. Early onset of obsessive-compulsive disorder and associated comorbidity. Depress Anxiety. 2009;26:1012-7.

43. Jaisoorya TS, Janardhan Reddy YC, Srinath S. Is juvenile obsessive-compulsive disorder a developmental subtype of the disorder?--Findings from an Indian study. Eur Child Adolesc Psychiatry. 2003;12:290-7.

44. Bolton D, Rijsdijk F, O'Connor TG, Perrin S, Eley TC. Obsessivecompulsive disorder, tics and anxiety in 6-year-old twins. Psychol Med. 2007;37:39-48. Epub 2006 Sep 26

45. Verkerk AJ, Mathews CA, Joosse M, Eussen BH, Heutink P, Oostra BA, et al. CNTNAP2 is disrupted in a family with Gilles de la Tourette syndrome and obsessive compulsive disorder. Genomics. 2003;82:1-9.

46. Cuker A, State MW, King RA, Davis N, Ward DC. Candidate locus for Gilles de la Tourette syndrome/obsessive compulsive disorder/ chronic tic disorder at 18q22. Am J Med Genet A. 2004;130A:37-9.

47. Peterson BS, Thomas P, Kane MJ, Scahill L, Zhang H, Bronen R, et al. Basal Ganglia volumes in patients with Gilles de la Tourette syndrome. Arch Gen Psychiatry. 2003;60:415-24.

48. Stephens RJ, Sandor P. Aggressive behaviour in children with Tourette syndrome and comorbid attention-deficit hyperactivity disorder and obsessive-compulsive disorder. Can J Psychiatry. 1999;44:1036-42.

49. Robertson MM, Banerjee S, Eapen V, Fox-Hiley P. Obsessive compulsive behaviour and depressive symptoms in young people with Tourette syndrome. A controlled study. Eur Child Adolesc Psychiatry. 2002;11:261-5.

50. Wang PW, Huang MF, Yen CF, Huang RR. Diagnosis and treatment of comorbidities of Tourette's syndrome and bipolar disorder in a 10-year-old boy. Kaohsiung J Med Sci. 2009;25:608-12.

51. Kerbeshian J, Burd L, Klug MG. Comorbid Tourette's disorder and bipolar disorder: an etiologic perspective. Am J Psychiatry. 1995; 152:1646-51.

52. Berthier ML, Kulisevsky J, Campos VM. Bipolar disorder in adult patients with Tourette's syndrome: a clinical study. Biol Psychiatry. 1998;43:364-70.

53. Kirov R, Kinkelbur J, Banaschewski T, Rothenberger A. Sleep patterns in children with attention-deficit/hyperactivity disorder, tic disorder, and comorbidity. J Child Psychol Psychiatry. 2007;48:561-70.

54. Thompson MD, Comings DE, Abu-Ghazalah R, Jereseh $\mathrm{Y}$, Lin $L$, Wade J, et al. Variants of the orexin2/hcrt2 receptor gene identified in patients with excessive daytime sleepiness and patients with Tourette's syndrome comorbidity. Am J Med Genet B Neuropsychiatr Genet. 2004;129B:69-75.

55. Gadow KD, DeVincent CJ. Clinical significance of tics and attentiondeficit hyperactivity disorder (ADHD) in children with pervasive developmental disorder. J Child Neurol. 2005;20:481-8. 
56. Baron-Cohen S, Scahill VL, Izaguirre J, Hornsey H, Robertson MM. The prevalence of Gilles de la Tourette syndrome in children and adolescents with autism: a large scale study. Psychol Med. 1999;29:1151-9.

57. Baron-Cohen S, Mortimore C, Moriarty J, Izaguirre J, Robertson M. The prevalence of Gilles de la Tourette's syndrome in children and adolescents with autism. J Child Psychol Psychiatry. 1999;40:213-8.

58. Zappella M. Early-onset Tourette syndrome with reversible autistic behaviour: a dysmaturational disorder. Eur Child Adolesc Psychiatry. 2002;11:18-23.

59. Ivarsson $\mathrm{T}$, Melin $\mathrm{K}$. Autism spectrum traits in children and adolescents with obsessive-compulsive disorder (OCD). J Anxiety Disord. 2008;22:969-78. Epub 2007 Oct 24.

60. Kerbeshian J, Peng CZ, Burd L. Tourette syndrome and comorbid early-onset schizophrenia. J Psychosom Res. 2009;67:515-23.

61. Müller N, Riedel M, Zawta P, Günther W, Straube A. Comorbidity of Tourette's syndrome and schizophrenia-biological and physiological parallels. Prog Neuropsychopharmacol Biol Psychiatry. 2002;26:1245-52.

62. Barbanti P, Fabbrini G. Migraine and Tourette syndrome. Arch Neurol. 2004;61:606-7; author reply 607.

63. d'Onofrio F, Barbanti P, Petretta V, Casucci G, Mazzeo A, Lecce B, et al. Migraine and movement disorders. Neurol Sci. 2012;33:S55-9.
64. Myers B, Pueschel SM. Tardive or atypical Tourette's disorder in a population with Down syndrome? Res Dev Disabil. 1995;16:1-9.

65. Schneider SA, Robertson MM, Rizzo R, Turk J, Bhatia KP, Orth $M$. Fragile $X$ syndrome associated with tic disorders. Mov Disord. 2008;23:1108-12

66. Fontenelle LF. Diogenes syndrome in a patient with obsessivecompulsive disorder without hoarding. Gen Hosp Psychiatry. 2008;30:288-90.

67. Stewart JT, Williams LS. Tourette's-like syndrome and dementia. Am J Psychiatry. 2003;160:1356-7.

68. Müller N, Riedel M, Förderreuther S, Blendinger C, Abele-Horn M. Tourette's syndrome and mycoplasma pneumoniae infection. Am J Psychiatry. 2000;157:481-2.

69. Pio-Abreu, JL. Elementos de psicopatologia explicativa. 1a ed. Lisboa: Fundação Calouste Gulbenkian; 2012.

\section{Correspondence:}

Bárbara R. Ferreira

Rua Dr. Paulo Quintela, 257, 10 N, 3030

Coimbra, Portugal

Tel.: +351934145272

E-mail: barbara.roqueferreira@gmail.com 